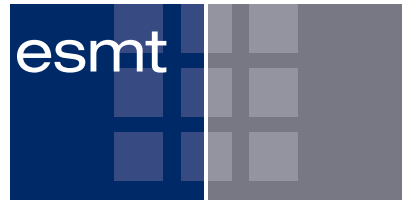

April 15, 2010

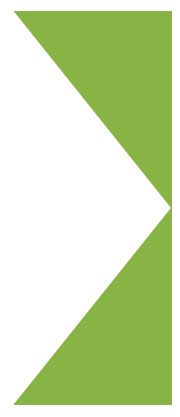

\title{
ESMT
}

WORKING PAPER

ESMT No. 08-004 (R1)

\section{Estimating Critical Mass in the Global Cellular Telephony Market}

Michal Grajek, ESMT

Tobias Kretschmer, Ludwig-Maximilians-Universität München

ISSN 1866-3494 


\title{
Abstract
}

\section{Estimating Critical Mass in the Global Cellular Telephony Market}

\author{
Author(s) ${ }^{\dagger}$ : Michal Grajek, ESMT \\ Tobias Kretschmer, Ludwig-Maximilians-Universität München
}

Critical Mass is a common feature of technology diffusion processes. We develop a structural model of demand with network effects to provide a rigorous definition of critical mass as a function of installed base, price and network effects. Using data from the digital cellular telephony market, we identify critical mass phenomena and find that differences in the critical mass point in different countries rest mainly on different countries' socioeconomic characteristics and the extent of competition in a country. This application illustrates that our demand model can be operationalized easily and can generate theoretically grounded empirical insights about critical mass phenomena.

Keywords: critical mass, network effects, technology diffusion, cellular telephony

J EL Classification: C53, L14, M37

Please note that this is a revision of the ESMT working paper No. 08-004 with the title 'Critical Mass' published June 13, 2008.

$+\quad$ We thank conference participants at WIEM 2007 (Warsaw), ITS 2007 (Istanbul), EARIE 2007 (Valencia), AOM2009 (Chicago), Luís Cabral, Manfred Schwaiger, Luc Wathieu and seminar audiences at ESMT and LMU Munich for helpful comments on an earlier draft, and Jan Krancke for data access.

Contact: Michal Grajek; ESMT, Schlossplatz 1, 10178 Berlin, Germany; Tel: +49 (0)30 21231 1047, Email: grajek@esmt.org. 


\section{Introduction}

Successful new technologies and innovations typically diffuse in an S-shape throughout the economy. Technology managers, marketing specialists and industry observers are especially interested in the point on the diffusion curve when the technology eventually "takes off" (Agarwal and Bayus, 2002; Lee et al., 2003; Golder and Tellis, 1997) and penetrates the mass market. For interactive technologies with network effects or social contagion, reaching this point is often the difference between success and failure, as a technology without sufficient users is not attractive for further adopters. Specifically in interactive markets, critical mass often describes the point at which a technology becomes attractive to a large share of the population (Lee et al.,2003; Loch and Huberman, 1999).

What, then, is critical mass? Starting with Schelling (1978), critical mass is assumed to be qualitatively different from "normal" episodes of technology diffusion. One of the simplest and most intuitive definitions comes from Rogers (2003), who states that upon reaching critical mass, "diffusion becomes self-sustaining" (p. 243), whereas most conventional technology diffusion processes rely on heterogeneous consumers and price decreases and/or quality increases (Loch and Huberman, 1999; Grajek and Kretschmer, 2009). Existence of critical mass, on the other hand, relies on a rapidly evolving endogenous process over time, e.g. network effects that spur diffusion even in the absence of price decreases. The link between technology diffusion and network effects is well-established (Rohlfs, 1974; Granovetter, 1978; Markus, 1987; Cabral, 1990, 2006; Loch and Huberman, 1999), and the literature identifying multiple stable equilibria separated by an unstable one (Katz and Shapiro, 1985; Economides and Himmelberg, 1995) characterizes the transition from one stable equilibrium to the other as critical mass.

We develop a simple structural model demand of a non-durable network good or service with an explicit view on its ease of empirical implementation. We use the logic of multiple 
equilibria and endogenous diffusion outlined above to show that critical mass - a selfsustaining diffusion process - will only emerge if boundary conditions on the strength of network effects, the size of the installed base, and the current market price, are met. We find that these three parameters are substitutes in terms of reaching critical mass: For stronger network effects, critical mass will be reached for higher prices and lower installed bases, for a higher installed base, network effects can be weaker and prices higher for critical mass to still exist, and so on. We then use our model to estimate a demand model of the global cellular telephony industry between 1998 and 2007. We find that demand for cellular services indeed displayed critical mass phenomena worldwide, and that differences across countries depend mainly on sociodemographic characteristics and the extent of competition in a country.

Our paper makes two contributions to the literature on new technology diffusion: First, we operationalize the theoretical model of network effects by Cabral (1990) for use in an empirical setting, thus offering practitioners and researchers a simple way of determining critical mass, i.e. whether a technology is likely to have periods of endogenous and rapid diffusion. Here, we see our approach as complementary to existing approaches focusing on the adoption dynamics of durable goods with indirect network effects (e.g. Dubé et al., 2009; Gowrisankaran and Stavins, 2004). Our approach also complements simulation models tracing industry dynamics and transitions (Lee et al., 2003; Loch and Huberman, 1999) as we derive information about the demand conditions and especially the extent of network effects in real-life markets which can then be used to feed simulation models. Moreover, the empirical model resulting from our approach has two important advantages: (i) it imposes very modest data requirements and (ii) it simplifies to the seminal Bass (1969) diffusion equation under certain conditions.

Second, we show for the case of digital cellular telephony that critical mass was a global phenomenon and that estimates from different subsamples of markets are largely similar so 
that results from earlier cohorts can be used to predict critical mass in markets which launch the technology later. ${ }^{1}$ Our results on critical mass in cellular telephony show that critical mass is a function of both installed base and price, the latter being much more important. Specifically, we estimate that cellular telephony would have "taken off" without any installed base at an approximate price of 25 US cents per minute. Take-off occurs at a slightly higher price (28 US cent) when the installed base of subscribers amounts to some $30 \%$ of the population, suggesting that installed base can only substitute for the "right" price to a very limited extent. We also find that in estimating long-run demand in emerging network markets, it is important to instrument for the endogeneity of prices in the demand estimations as otherwise most of the demand increase will be attributed (wrongly) to network effects.

In the next section, we summarize prior literature on the cellular telephony market and technology diffusion with network effects. In Section 3, we introduce a structural model of demand to recover the strength of network effects as estimated parameters. In Section 4 we use data from the early digital mobile telephony industry to identify and simulate counterfactual values of critical mass and check how sensitive critical mass is to changes in structural parameters of the model. Section 5 concludes.

\footnotetext{
${ }^{1}$ This result is analogous to the findings by Mahajan et al. (1995) in a related domain, who show that the diffusion parameters in a Bass (1969) model are remarkably similar across products and countries, thus allowing inferences from one process about future processes.
} 


\section{Related Literature}

Much of the empirical literature on emerging network technologies can be divided in two streams - competition between emerging technologies and diffusion of a new technology. ${ }^{2}$ The first stream looks at explaining and documenting the dynamics of competing standards (Jenkins et al., 2004; Dubé et al., 2009; Cantillon and Yin, 2008; Tellis et al., 2009) and the phenomenon of market tipping (Shapiro and Varian, 1999). The second line of research studies the impact of network effects on the diffusion speed or adoption timing of a new technology (Saloner and Shepard, 1995; Gowrisankaran and Stavins, 2004) or a set of complementary technologies (Gandal et al., 2000). Many of these studies find significant network effects resulting in faster diffusion, as predicted by Rogers (2003). None of these papers, however, address the possibility of a rapid, almost discontinuous diffusion path. Indeed, they estimate smooth curves that can differ only in the speed of diffusion and not in their general shape. By construction, the existence of critical mass cannot be explored in these studies.

The literature on critical mass phenomena has developed largely in parallel to work on network effects. The theoretical literature on critical mass derives theoretical or conceptual explanations of why certain markets display critical mass phenomena. Markus (1987) uses a set of qualitative indicators to identify interactive media markets with critical mass behavior and finds the underlying production function and consumer heterogeneity to be especially important in such markets. Loch and Huberman (1999) identify in a simulation model that rapid (i.e., critical mass-like) transition from an old to a new standard can occur if consumers have a high rate of experimentation and the new technology improves rapidly. Finally, Cabral $(1990,2006)$, who proposes a model similar in spirit to ours, finds that the equilibrium adoption path might display "catastrophe points", that is, critical mass phenomena. These 
catastrophe points occur only if network effects are sufficiently strong. All of the above papers outline a number of circumstances (e.g. demand and network parameters, production technologies, market structure) under which critical mass-like phenomena can occur within an industry, and most provide anecdotal evidence of market dynamics consistent with their models of critical mass, although none test their findings using an econometric model and real data. $^{3}$ The empirical work on critical mass focuses on identifying a percentage typically varying between 10\% (Mahler and Rogers, 1999) and 25\% (Cool et al., 1997) - of market potential as critical mass, which is assumed to be the penetration level at which diffusion speed picks up significantly. This closely relates to work on sales takeoff (Golder and Tellis, 1997; Agarwal and Bayus, 2002; Tellis et al., 2003), which looks for heuristic rules of the link between early sales growth and long-term product success. Sales take-off represents the transition from a product appealing predominantly to pioneers and early adopters to one that is adopted by the mass market (Rogers, 2003; Mahajan et al., 1990), which might occur earlier for interactive innovations (Mahler and Rogers, 1999).

Our empirical setting, the global cellular telephony industry, has been studied in some detail previously. Existing work is united in their findings that the technology displays network effects in adoption (Gruber and Verboven, 2001; Koski and Kretschmer, 2005; Grajek and Kretschmer, 2009). These papers find that the diffusion process for mobile telephony varies across countries and groups of countries, which suggests that different technological, socioeconomic, and regulatory factors affect the diffusion process. However, most industrialized countries had periods of rapid diffusion, which most existing models were not able to empirically distinguish from critical mass (which does not rest on price decreases or exogenously changing technologies), which is what our model and subsequent estimation

\footnotetext{
${ }^{2}$ The theoretical literature on network effects will not be reviewed in detail. Recent surveys include Koski and Kretschmer (2004), Farrell and Klemperer (2007) and Stremersch et al. (2007).
} 
proposes to do. One exception is Grajek (2009), who uses a similar model to ours, but focuses on compatibility across competing networks rather than critical mass. Consequently, he uses operator-level data from a single market (Poland) whereas we study multiple geographic markets at the aggregate level.

\section{Theoretical Model}

\subsection{Willingness to Pay and Network Effects}

We propose a model of demand with network effects. Suppose that at each time, $t$, consumers decide, depending on the net benefit, whether or not to subscribe to a service. ${ }^{4}$ Examples include subscription to a payment system such as a credit card or to a communication service such as e-mail or mobile telephony. The service displays network effects such that the installed base of adopters (subscribers) affects consumer willingness to pay.

There is a measure one of infinitely lived consumers with unit demand for the service influenced by consumer type and the installed base of users. Consumer v's preferences are represented by the willingness-to-pay function $u\left(v, x_{t-\delta}\right)$, where $v$ is the individual preference parameter, $x_{t-\delta}$ is lagged network size at time $t$, and the perception lag $\delta$ is a non-negative number. We further assume the individual preference parameter $v$ to be distributed according to a $\operatorname{CDF} F(v)$, and that $u\left(v, x_{t-\delta}\right)$ is strictly increasing and continuous in $v$. The parameter $v$ thus establishes a rank ordering of consumers by willingness to pay that we assume to be invariant with respect to changes in $x_{t-\delta}$.

We include lagged network size $x_{t-\delta}$ in the willingness-to-pay function for two reasons, (1) it captures network effects in demand for the good, and (2) the perception lag $\delta$ is an

\footnotetext{
${ }^{3}$ Economides and Himmelberg (1995) develop a theoretical model and test it using a time series of fax technology in the US. However, their definition of critical mass differs from ours - they refer to critical mass as the minimum equilibrium network size.

${ }^{4}$ Our theoretical model draws on Cabral (1990).
} 
equilibrium selection device that yields a unique diffusion path for the network. ${ }^{5}$ But it also raises questions about consumer rationality. Why would a consumer base a purchasing decision on events that occurred some time ago? We offer two justifications, (1) because small perception lags will result in near-rational behavior, our model effectively approximates rationality, and (2) realistically, consumers will not have information on the current numbers of subscribers, but rather to previously published figures, resembling a perception lag. ${ }^{6}$ We therefore believe our assumption of a perception lag to be both realistic and necessary to the development of an empirically tractable strategy for identifying critical mass short of having data on consumer expectations. Working with lags seems a sensible alternative, although the approximation of rational expectations through lags clearly depends on the frequency of observations.

\subsection{Short-Run and Long-Run Subscription Demand}

At time $t$, consumer $v$ decides whether to subscribe by considering the net utility from joining:

$$
u\left(v, x_{t-\delta}\right)-p_{t}
$$

There is one market price, $p_{t}$. If (1) is non-negative, the consumer will join, otherwise not. ${ }^{7}$

Denote by $v_{t}^{*}$ the type of the consumer indifferent between joining or staying out at time $t$. His type is determined by the following equation:

$$
u\left(v_{t}^{*}, x_{t-\delta}\right)=p_{t}
$$

\footnotetext{
${ }^{5}$ As shown in Cabral (1990), when $\delta=0$ there are infinitely many equilibrium diffusion paths. A positive $\delta$ implies that consumers cannot coordinate their subscription decisions, leading to a unique equilibrium diffusion path. An alternative approach followed in Economides and Himmelberg (1995) is to allow consumers to coordinate in order to reach the critical mass.

${ }^{6}$ Indeed, Cabral (1990) shows that for infinitely small $\delta$, consumers are rational because their subscription decisions are identical to the ones made by forward-looking consumers.

7 This "static" decision rule is appropriate for non-durable goods, and is relaxed in the Appendix.
} 
As $v$ orders consumers by their willingness to pay, all consumers with $v \geq v_{t}{ }^{*}$ will join. Define

$$
H\left(v_{t}^{*}\right) \equiv 1-F\left(v_{t}^{*}\right)
$$

such that $H_{i}($.$) equals the number of consumers in the network at time t$. The state equation describing network size at time $t$, that is, short-run demand, is then given by:

$$
\text { (4) } \quad x_{t}=H\left(v_{t}^{*}\right)
$$

In steady state, no consumer can increase utility by joining or leaving; the network stays constant over time, which gives the following long-run demand condition:

$$
x_{t}=x_{t-\delta} .
$$

Long-run demand is reached when the market is fully saturated and there are no more consumers to fuel further diffusion. This need not be the case, however, as long-run demand can also fall short of full saturation depending on prices and consumer preferences. This is an important feature that differentiates our model from the Bass (1969) model, in which full saturation is always reached in the long run. In other words, our model can accommodate failed products. Note also that the steady-state equilibrium in our model coincides with the static fulfilled-expectations equilibrium, which is commonly used in the economics literature (Rohlfs, 1974 and Katz and Shapiro, 1985).

\subsection{Network Dynamics: Critical Mass and Diffusion Takeoff}

We assume the CDF of $F(v)$ and the willingness-to-pay function $u\left(v, x_{t-\delta}\right)$ to be continuously differentiable in all arguments. In Cabral's (1990) analysis of the equilibrium network size path shows that for sufficiently strong network effects and lag length $\delta$ approaching zero, the equilibrium adoption path is unique and discontinuous as described by 
equation (4). Because $H($.$) maps the change in network size from time t-\delta$ to $t$, it is convenient to think of it as of a function of lagged network size $x_{t-\delta}$. To see how network externalities and price affect diffusion, we calculate the derivatives of $H(\cdot)$ with respect to lagged network size $x_{t-\delta}$ and price $p$ in the Appendix. The slope of $H(\cdot)$ increases in the strength of network effects measured by $\eta \equiv \frac{\partial u\left(v_{t}{ }^{*}, x_{t-\delta}\right)}{\partial x_{t-\delta}}$, as shown in Lemma 1 in the Appendix.

Figure 1 illustrates the diffusion dynamics. In the top panel we show $H(\cdot)$ as a function of lagged network size $x_{t-\delta}$. Given the steady-state condition (5), the long-run equilibrium network sizes coincide with the fixed points of $H(\cdot)$. Without network effects, $H(\cdot)$ is a horizontal line with a single fixed point. A combination of positive network effects and a bell-shaped distribution of types $v$ can result in a function $H($.$) with multiple long-run$ equilibria similar to that shown in Figure 1. The dynamics in our model let us discriminate among these multiple steady states. Suppose market price is $p^{*}$ in Figure 1. According to state equation (4), network size will evolve as indicated in the top panel. If it starts at some size $x<x^{\prime}$, it will eventually reach $x^{0}$; if $x>x^{\prime}$, it will end up in $x^{\prime \prime}$. If $x=x$, it will stay there, but any arbitrarily small shock will lead to an equilibrium at $x^{0}$ or $x^{\prime \prime}$. Therefore, $x^{0}$ and $x$ '’ are stable steady states, whereas $x$ ' is unstable.

INSERT FIGURE 1 ABOUT HERE

Figure 1: Stable vs. unstable equilibria

We can apply the same logic to any price $p$. Lemma 2 in the Appendix states that lowering price shifts $H($.$) upwards (although not necessarily in parallel). Drawing the steady$ 
states for each price gives long-run demand $D(p)$ in the lower panel of Figure 1, which lets us define a critical mass point:

\section{PROPOSITION 1. Downward-sloping parts of long-run demand $D(p)$ consist of stable}

equilibria, whereas upward-sloping parts are unstable, that is, consist of critical-mass points. Network effects must be sufficiently strong for unstable equilibria to exist.

The intuition of Proposition 1 is that downward-sloping parts of the demand correspondence are locally "well-behaved," that is, every price $p$ has a single corresponding long-run network size given by $D(p)$. Conversely, critical mass points are unstable in the sense that they divide regions of attraction towards the stable equilibria. When the installed base reaches critical mass, there is a qualitative change in the diffusion process; a switch from low-adoption to high-adoption equilibrium occurs and diffusion takes off without a change in prices or qualities.

Now consider a case with no initial installed base and falling prices over time. That is, let $p_{t}$ be a continuous and decreasing function of time, and let $p_{t=0}>p^{h}$ (as in Figure 1) and $x\left(p_{t=o}\right)$ be the unique steady-state network size given $p_{t=0}$. As price falls, network size initially follows the low-adoption steady state. Eventually, price reaches $p^{l}$ and network size jumps immediately to the high-adoption steady state and progresses along it. Formally, this diffusion pattern is correct for infinitely small $\delta$ (Cabral, 1990). If the perception lag is strictly positive, consumers are myopic with respect to network size, that is, they do not recognize that the network is going to grow in the current period. Consequently, equilibrium network size does not follow the steady-state equilibrium exactly, but approximates it. Instead of the discontinuous jump in diffusion, rapid takeoff occurs and diffusion is S-shaped. 
This dynamic perspective illustrates the equilibrium selection rule implicitly assumed in our model by the lag structure, as we do not rely on coordination among consumers to obtain a discontinuous jump. ${ }^{8}$ Instead, rapid diffusion emerges spontaneously at price $p^{l}$. For takeoff to occur at a price higher than $p^{l}$, the supplier needs to grow the installed base to critical mass level, for example through temporary discounts or free sampling. We can now formulate some predictions about the comparative static behavior of the critical mass point.

PROPOSITION 2. If sufficiently strong network effects exist to generate multiple steady-state equilibria, critical mass is reached at a lower (higher) installed base for lower (higher) price. Ceteris paribus, stronger network effects imply critical mass at a lower installed base and/or higher price.

The first part of Proposition 2 follows immediately from Proposition 1. Because the critical mass points are on the upward sloping part of the long-run demand function, a higher price implies higher critical mass and vice versa. The second part of Proposition 2 is also intuitive. With stronger network effects, it takes a smaller installed base to make a consumer with a given intrinsic valuation adopt if price and distribution of types are held constant.

\footnotetext{
${ }^{8}$ Note that it would be Pareto-optimal to jump to the larger steady-state network size before price falls below $p^{l}$. However, this would require the coordination of consumers' subscription decisions to reach critical mass.
} 


\subsection{Firm Strategies}

We do not model the supply side because we are interested in identifying conditions under which demand for a good displays critical mass phenomena. That is, given the demand conditions we identify in our model, decisionmakers can subsequently implement appropriate supply-side strategies (e.g. strategic pricing, free samples etc.) to reach and utilize critical mass dynamics. Moreover, from an econometric perspective, we do not need to impose any structure for the supply relation to be able to correctly estimate the network effect parameter and identify critical mass, as we can resolve endogeneity issues regarding the price variable via instrumental variable techniques.

\section{Empirical Implementation}

\subsection{Data}

We use country-level quarterly data from the Merrill Lynch Global Wireless Matrix on the global cellular telephony market in the early stages of the first digital generation $(2 \mathrm{G})$, updated to the third quarter of 2007 and covering 36 countries and 36 quarters. ${ }^{9}$ The decade from 1998 onwards is one of the most dynamic episodes in the global mobile phone market with global penetration rates increasing from $6 \%$ to more than $50 \%$ (Grajek and Kretschmer, 2009). Since we define critical mass to be a function of both price and installed base, we require a sufficiently long period of price and diffusion figures per country as well as user data capture the critical mass point adequately, and quarterly data affords the necessary degrees of freedom for testing the robustness of our results with respect to the specification of the actual perception lag, which cannot be observed empirically.

\footnotetext{
${ }^{9}$ This data has been used is prior research (Grajek and Kretschmer, 2009; Genakos and Valletti, 2009). The following countries/markets are in the sample: Australia, Austria, Belgium, Brazil, Canada, China, Czech Republic, Denmark, Finland, France, Germany, Greece, Hong Kong, Hungary, Ireland, Israel, Italy, Japan, Korea, Malaysia, Mexico, Netherlands, New Zealand, Norway, Poland, Portugal, Russia, South Africa, Singapore, Spain, Sweden, Switzerland, Thailand, Turkey, UK, and the US.
} 
As mentioned above, one advantage of our model is that it imposes very modest data requirements. Table 1 shows descriptive statistics of the variables used in the empirical analysis. Mobile penetration and mobile penetration squared are calculated as ratios of the total number of cellular telephony subscribers to the population in a given country and the GDP per capita measures the average wealth of the population. The price variable measures the average price of a one-minute call in a given country and is defined as an average price across operators weighted by their respective penetration rates. ${ }^{10}$ Table 1 also reports the instrumental variable that we use to account for potential endogeneity of price in our demand equation. Following Grajek and Kretschmer (2009), we define it as an average price in other countries of the region. ${ }^{11}$

INSERT TABLE 1 ABOUT HERE

Finally, we construct three dummy variables, RICH, PIONEER, and COMP, which will be used to assess whether the estimates of network effects and critical mass differ across various country groups. RICH indicates countries with above-median GDP per capita in our sample, PIONEER captures countries that were among the first to introduce $2 \mathrm{G}$ cellular telephony and COMP indicates that there are at least three active cellular telephony providers in a given country. ${ }^{12,13}$

\footnotetext{
${ }^{10}$ The price for an individual operator, as obtained from the ML Global Wireless Matrix, is defined as the revenue from services divided by the total number of minutes on the operator's network.

${ }^{11}$ The regions are classified as follows: USA/Canada, Western Europe, Eastern Europe, Asia/Pacific, Africa, and Americas.

${ }^{12}$ The $2 \mathrm{G}$ cellular telephony was first introduced in Finland in 1992. We define PIONEER as a country which introduced 2G before 1993.

${ }^{13}$ In some countries the number of mobile providers increased from two to three during the period studied. The COMP dummy was then changed from zero to one, accordingly.
} 


\subsection{Functional Specification and Identification Issues}

Our next step towards operationalizing critical mass is to specify functional forms for the underlying demand model. The specification in this section has been chosen for three reasons, (1) it gives a simple linear (in parameters) diffusion equation that is convenient to work with empirically, (2) it generates the seminal Bass (1969) diffusion equation, and (3) it facilitates analysis based on multiple markets from which our data are drawn.

We specify consumer $v$ 's willingness-to-pay function as follows:

$$
u\left(v, X_{i, t-1}\right)=v+c X_{i, t-1}+d X_{i, t-1}^{2}
$$

where $c$ and $d$ are parameters that determine the extent of network effects, with the square term capturing possible nonlinearities, for example diminishing marginal network effects (Swann, 2002), and the network size $X_{i, t}$ is defined as the number of subscribers normalized by the population size in a given geographic market (i.e. country) in year $t\left(X_{i, t}=x_{i, t} / P O P_{i, t}\right){ }^{14}$ Thus, specification (6) assumes that network effects are a function of relative rather than absolute number of subscribers to facilitate multiple markets analysis. Moreover, we assume the preference parameter $v$ to be uniformly distributed over $\left(-\infty, a_{i, t}\right]$ with density $b_{i, t}>0$. This distribution of types implies that population size is allowed to exceed one (in fact, it is infinite) to avoid corner solutions. ${ }^{15}$ It is also country-and-time specific in that the distribution parameters are assumed to depend on the demographics in the following way:

$$
\begin{aligned}
& a_{i, t}=a_{0}+a_{1}(G D P / P O P)_{i, t} \\
& b_{i, t}=b P O P_{i, t} .
\end{aligned}
$$

\footnotetext{
${ }^{14}$ Note that in the empirical model, $\delta$ will be determined by data frequency. Consequently, we replace $\delta$ with 1 meaning "one period" from now.

${ }^{15}$ Alternatively, the distribution support could be bounded from below to limit the population of consumers and the bound assumed to be low enough to avoid corner solutions with all consumers subscribing.
} 
That is, the highest consumer type in the population depends on a country's GDP per capita and the extent to which aggregate demand reacts to price changes is determined by the country's overall population.

Given these functional forms, diffusion equation (4) becomes

$$
X_{i, t}=a_{0} b+a_{1} b(G D P / P O P)_{i, t}-b p_{i, t}+b c X_{t-1}+b d X_{t-1}^{2}
$$

The structural parameters of this model can be recovered from the coefficients of the following estimation equation:

$$
X_{i, t}=\alpha_{0}+\alpha_{1}(G D P / P O P)_{i, t}+\beta p_{i, t}+\gamma_{1} X_{i, t-1}+\gamma_{2} X_{i, t-1}^{2}+\varepsilon_{i, t},
$$

where $\varepsilon_{i, t}$ denotes the error term, which we allow to be heteroscedastic and correlated across time $t$, but not across markets $i$. The error term captures the effects of variables that affect subscriptions, but are not observed in our data set, e.g. marketing effort of operators, or the degree of non-price competition more generally, in each geographic market. Equation (10) simplifies to a multi-market version of the original Bass model if $\beta=0$ (i.e., price does not matter for network diffusion). To see this, rearrange the terms to obtain:

$$
X_{i, t}-X_{i, t-1}=\alpha_{0}+\alpha_{1}(G D P / P O P)_{i, t}+\beta p_{i, t}+\left(\gamma_{1}-1\right) X_{i, t-1}+\gamma_{2} X_{i, t-1}^{2}+\varepsilon_{i, t}
$$

The left-hand side of (11) corresponds to subscription sales at $t$ and the right-hand side is a square function of cumulative sales through period $t$ - 1 with a market-specific intercept, which is a straightforward extension of the Bass model to a multi-market context. In fact, a singlemarket version of (11) matches exactly the discrete analog of the Bass (1969) diffusion equation, as shown in Appendix A.3.

The estimates of coefficients in equation (10) identify the structural parameters of our model as follows: the highest consumer type in the population is identified via two parameters, $a_{0}=-\alpha_{0} / \beta$ and $a_{1}=-\alpha_{1} / \beta$, and the density of the distribution of types depends on 
the parameter $b=-\beta$. The network effects parameters $c$ and $d$ are identified via $-\gamma_{1} / \beta$ and $\gamma_{2} / \beta$, respectively. Thus, the network effects in our model are identified by separating the impact of installed base on current subscriptions from the impact of price. More generally, the installed base effect could also be due to other social contagion effects including social learning under uncertainty and social-normative pressures, as has been pointed out for aggregate diffusion models (Van den Bulte and Lilien, 2001; Van den Bulte and Stremersch, 2004). Our focus, however, is less on the source of the installed base effect than on its implications for critical mass, and we estimate the installed base parameters to gain insights about critical mass by simulating counterfactual steady states of the diffusion process.

Finally, the identification of structural parameters of our model in the data depends critically on the ability to consistently estimate the coefficients on the installed base variables in (10). One problem is the appropriate choice of the perception lag $\delta$. Unless we have more detailed information about how frequently the consumers update their estimate of installed base, the choice of perception lag will be ad hoc and in practice determined by the frequency of data. Another problem, pointed out by Hartmann et al. (2008) in relation to the Bass (1969) model, is that the relationship between the installed base and current network might be driven by serial correlation in sales-related unobservables over time. We address these concerns in the empirical section of the paper by comparing the estimated model using various perception lags. We also test for serial correlation of residuals in the estimated models to see if omitted unobservable variables are of potential concern.

\subsection{Baseline Estimation Results}

We estimate equation (10) with the data at hand using various estimation techniques to accommodate potential problems of endogeneity of prices (Grajek and Kretschmer, 2009), and use different lag lengths. Estimation results are reported in Table 2. Columns (1) - (3) 
report OLS results with $X_{t-1}$ referring to 1, 2, and 4 quarter lags, respectively, and columns (4) - (6) results from an instrumental variables (IV) approach using average price in other countries in the region as the instrument for price, as diffusion and price might be codetermined, again using different lag structures.

\section{INSERT TABLE 2 ABOUT HERE}

We first discuss the regression results and their robustness across specifications, then assess their implications for critical mass. Comparing our regression coefficients across the different specifications in Table 2, we see that both alternative lag structures and instrumenting for the price variable affect the magnitude, but not the significance, of the coefficients. Our preferred specification is IV because the price variable is likely to be endogenous in the model, as has been shown by previous work (Grajek and Kretschmer, 2009). Observe first that wealth positively affects penetration, as expected. The other coefficients also carry the expected signs and are consistently significant.

As expected, we find the price effect to be larger in our IV regressions because we correct for endogeneity and therefore reverse causality (i.e., penetration affecting price). In particular, we would expect failing to control for this to bias the price effect downwards because operators might have an incentive to increase prices (or at least decrease at a slower pace) as the installed base grows.

We also observe that using higher lags of the penetration variable leads to higher serial correlation in the error term and a higher magnitude of the installed base coefficients. With a one-quarter lag, the estimated serial correlation is fairly low, 0.055 in the OLS regression and 0.223 in the IV regression, suggesting that omitted sales-related unobservables are of some concern and might bias our estimates. We control for this to some extent by using standard errors that are robust to heteroscedasticity and serial correlation. With higher lags, serial 
correlation increases to almost 0.8 , which is evidence of serious model misspecification. Longer observation lags generate higher estimates of network effects as diffusion between two times is attributed to a lower installed base if it is further in the past. In conjunction with the evidence of model misspecification with longer lags, we therefore prefer the one-quarter lag structure.

Our estimations let us recover the structural parameters of our model as outlined above.

INSERT TABLE 3 ABOUT HERE

The model parameters reported in Table 3 can be used to identify combinations of installed base $\left(X_{t-1}\right)$ and prices $\left(p_{t}\right)$ that give an upward-sloping long-run demand curve - points at which critical mass occurs. Figure 2 gives the steady-state demand functions for the six models derived from our model parameters.

INSERT FIGURE 2 ABOUT HERE

Figure 2: Critical mass in the cellular telephony market: Simulation of long-run demand using estimated model parameters

We see from Figure 2 that in all of our specifications the global mobile telephony market displays critical mass, that is, there is an upward-sloping part of the demand curve for a given price range and installed base. In the OLS regressions, critical mass exists if average price per minute is between 31 and 37 US cents. Below this range, the market does not exhibit critical mass, and only the high-adoption equilibrium exists; above it, demand is zero. Within the price range, critical mass ranges from $0 \%$ to approximately $30 \%$ installed base depending on price. For example, for prices slightly below 37 US cents, an installed base of roughly $30 \%$ of the market would be required to facilitate the jump from the low-adoption to the high- 
adoption equilibrium. ${ }^{16}$ Conversely, if price was around 31 US cents, the diffusion process would take off immediately at zero installed base converging to approximately $60 \%$ penetration in the long run. Thus, penetration pricing to generate immediate market presence in a completely unpenetrated market (i.e. $X_{t-1}=0$ ) will be effective only for prices of $31 \mathrm{US}$ cents and below. For any higher price, additional marketing instruments such as promotions, trial versions, and expectations management would be needed to generate the level of expectations or actual installed base required to reach critical mass.

In our IV regressions, in which the estimated price effect is stronger, there are still significant network effects, although the price range in which there is critical mass is much smaller, ranging from 25 to 28 US cents depending on the lag structure chosen. However, the fact that we obtain critical mass even when attributing most changes in demand to price changes suggests that this is a real phenomenon in the mobile phone market. Further, although the magnitude of our regression coefficients changes, our estimates of critical mass remain almost unchanged with different lag structures, which makes all the more attractive an approach that emphasizes long-run market estimates over period-by-period fluctuations that depend heavily on the econometrician's definition of an (unobserved) observation lag.

Our estimates of critical mass depart from the traditional estimates in the marketing literature in one important way: they explicitly recognize the impact of price, as advocated by Golder and Tellis (1997). Whereas most marketing work estimated the market penetration needed for takeoff of a new product (or critical mass) to range from some $2.5 \%$ (Rogers, 1983; Sultan et al. 1990; Golder and Tellis, 1997) to 10\% (Mahler and Rogers, 1999) to 25\% (Cool et al., 1997) our estimates suggest that the primary driver of takeoff is price. ${ }^{17}$ On average, at greater than 28 US cents, subscriptions do not take off and market penetration

\footnotetext{
${ }^{16}$ The exact number, $31.5 \%$ of the market at the price of 36.8 US cents, is derived as the maximum of the estimated demand curve.
} 
remains small. ${ }^{18}$ Once price passes this threshold, takeoff occurs, leading eventually to adoption by the mass market. In the next sections we look at the differences across national mobile phone markets in more detail, and explore how sensitive predicted steady-state demand is to variations in each model parameter.

\subsection{Separating Country Groups}

Our model above pooled the entire sample of countries to estimate a global range of priceinstalled base combinations that generate critical mass phenomena. Although we take into account between-country heterogeneity in our estimation of $a_{i, t}$ and $b_{i, t}$, it is conceivable that the degree of network effects, $c$ and $d$, also varies across countries or groups of countries. This could mean, for example, that some countries do not display critical mass while others do, or that critical mass might exist over different prices ranges in different economic areas. This matters greatly for international product launch strategies. One way to see if different approaches for different country groups are necessary is to see if network effects vary across country groups. Three important distinctions among countries are if they are "rich" or "poor," and if they are "pioneers" or "followers" regarding a particular technology, and if the mobile telephone market is "highly competitive" or "not highly competitive". We assess the differences in coefficients by creating three corresponding dummy variable - RICH, PIONEER and COMP - and interacting with the (linear and squared) installed bases. Results for the one-quarter lag OLS and IV regressions are given in Table 4.

INSERT TABLE 4 ABOUT HERE

\footnotetext{
${ }^{17}$ This is apparent in the IV results, where the steady-state demand function is nearly horizontal at the price of 28 US cents.

${ }^{18}$ To be precise, the model predicts that for these higher prices the number of subscribers will be exactly zero, a property that is driven by the uniform distribution of types in our model. More generally, one can think of zero market penetration as a small penetration of specialized users who are qualitatively different from mass-market users.
} 
All interaction terms in table 3 capturing the rich and the pioneer countries are insignificant, which suggests that the extent of network effects is fairly robust in these different subsamples. In other words, the economic and strategic implications of critical mass for mobile phone diffusion are likely to be fairly similar across these groups of countries, suggesting that critical mass was, indeed, a global phenomenon in mobile telephony.

Interestingly however, we find that the competitiveness of the market matters for critical mass. As can be seen in Table 4, the interaction terms of installed base and competitiveness dummy are significant both in the OLS and IV regressions. Thus, network effects in competitive markets seem weaker when mobile penetration is small, as indicated by the negative coefficient on linear mobile penetration interaction, but stronger when penetration is high, as shown by the positive coefficient on the squared penetration interaction. These different coefficients for competitive and less competitive markets lead to different long-run demand functions, as shown in Figure 3. Competitive markets have less tendency to display critical mass phenomena. Specifically, the long-run demand based on our IV estimates, shows that for competitive markets there is no combination of prices and installed base that generates critical mass, while there is a range of prices between 30 and 36 US cents in less competitive markets with critical mass phenomena. At first glance, this seems counterintuitive as competitive markets are typically characterized by lower prices and faster diffusion, even after controlling for prices (Koski and Kretschmer, 2005). However, note that we are estimating the demand structure under two different competitive regimes rather than the evolution of prices in these markets. Our results suggest that network effects as they enter consumer demand are lower in competitive regimes, especially for small values of the installed base, which is when critical mass matters most. One interpretation is that competing networks are less than perfectly compatible (due to, for example, on-net call discounts), suggesting that small economy-wide network sizes are fragmented, or splintered, across 
different competitors, leading to even lower network utility than in a hypothetical monopolistic (or duopolistic) case with the same overall network size (Kretschmer, 2008). ${ }^{19}$ Therefore, diffusion in competitive markets may be driven more by ongoing decreases in prices rather than self-sustaining processes around the critical mass point.

INSERT FIGURE 3 ABOUT HERE

Figure 3: Separating country groups: Long-run demand and competitiveness

\subsection{Sensitivity Analyses}

In this section, we show how sensitive critical mass is to changes in the parameters of our model, especially network effects and the demographic parameters that determine demand. We first change the estimated network effects parameters by $10 \%$ from the estimated parameter in our preferred (IV with one-quarter lag) regression in Section 4.5.1, and change the demographic parameters (income and density) in 4.5.2.

\subsubsection{Increase in Network Effects}

The effect of a change in network effects is shown in Figure 4. The other structural parameters, $a$, the maximum willingness to pay for a subscription when network size is zero, and $b$, the density of the distribution of consumer types, are left at the values implied by our preferred regression (4) in Table 3 (i.e., $a=0.277, b=0.623$ ). ${ }^{20}$ We increase the value of each parameter in question by $10 \%$. In the left panel, we can see that as network effects become stronger (i.e., increasing $c$ ), the demand function becomes more concave and features a larger upward-sloping portion (critical mass). In the right panel, we find that a change in $d$ (i.e., changing the role of decreasing marginal network effects) does not have much of an

\footnotetext{
${ }^{19}$ On-net tariffs are prices charged for calling a number within the same operator's network, off-net tariffs refer to outside calls. The existence of on-net discount (lower on-net than off-net price) results in network effects. See Grajek (2009) for a discussion of compatibility between cellular networks.

${ }^{20}$ The parameter $a$ is evaluated at the mean income in the sample: $0.277=0.207+0.003^{*} 21.47$.
} 
impact on the occurrence of critical mass. In keeping with Proposition 2, we observe critical mass (for a given price $p$ ) earlier when network effects become stronger (i.e., increasing $c$ or d). This effect is much more pronounced in the left panel of Figure 4, as $c$ affects the extent of network effects more than $d$ for small network sizes. Critical mass therefore is quite sensitive to the parameter $c$ in our model.

INSERT FIGURE 4 ABOUT HERE

Figure 4: Sensitivity of long-run demand to changes in network effect parameters

\subsubsection{Changes in Price Sensitivity and Consumer Stand-Alone Valuation}

We now show the effects of changes in the distribution of consumer types, again using the values of the other structural parameters implied by regression (4) in Table 3. Figure 5 shows the effects of changes in these parameters for network effects set at $c=1.674$ and $d=-0.190$. In the left panel, we evaluate the highest-consumer-type parameter $a_{i, t}$, as defined in (7), at the maximum and minimum income in our sample. We can see that for larger values of $a_{i, t}$, critical mass is reached at higher prices, and, as expected, there is a shift in the demand curve such that richer countries will reach critical mass more easily. That is, although all countries in our sample display critical mass (as seen in section 4.2), it will be reached at higher prices for higher-income countries. In the right panel, we see that the impact of increased density of consumer types' distribution, $b$, which determines short-run price sensitivity of demand, resembles the impact of stronger network effects. With higher $b$, more consumers are willing to subscribe at each price. If $b$ is sufficiently high, network effects can "kick in" early, generating critical mass at relatively high prices. Again, this is intuitively appealing as countries might have different "densities" of high-value consumers that will determine how 
quickly critical mass is reached. Many consumers willing to purchase a good at high prices might be enough to generate critical mass and make the mass market adopt.

\section{INSERT FIGURE 5 ABOUT HERE}

\section{Figure 5: Sensitivity of long-run demand to changes in taste distribution parameters}

Our simulations demonstrate that in otherwise identical markets (i.e., with the same structural parameters and price sensitivity), markets with more pronounced network effects can display critical mass phenomena while others with more moderate network effects (or strong congestion effects) do not. Regarding the price sensitivity of demand, more pricesensitive goods are more likely to display critical mass phenomena, suggesting that small changes in price might generate more extreme changes in demand for a good than might be anticipated from a static demand curve.

It is important to emphasize that the possible shape of steady-state demand as simulated in Figures 2 to 5 is heavily influenced by our functional form assumptions. With the assumptions of uniform and bounded valuations, we do not obtain two downward-sloping parts in our demand correspondence as in Figure $1 .{ }^{21}$ However, the simulated demand functions in Figures 2 to 5 approximate the more general function in Figure 1 because the vertical axis above the minimum critical mass point (i.e., $X=0$ for sufficiently high $p$ ) is also part of long-run demand. Thus, the intuition behind critical mass dividing the high and low demand regions (zero in the model above) holds true even for our simplifying functional assumptions.

\section{Conclusion}

\footnotetext{
${ }^{21}$ Figure 1 implies a long tail in the distribution of types that captures consumers with very high willingness to pay even if no one else subscribes (the innovators).
} 
We developed a model of demand for a new network technology to identify critical mass phenomena. The main strength of our approach is that we propose a simple theoretical model that can easily be implemented empirically. Most existing papers either propose a rigorous theoretical model or provide a simple empirical heuristic. We define critical mass points as combinations of price, network effects, and installed base that lead to multiple equilibria. The parameters recovered from the empirical implementation of our model can be used to identify and analyze critical mass, the point at which "further diffusion is self-sustaining" (Rogers, 2003), which, in our model, implies that (rapid) diffusion occurs without any further changes in price. In our empirical implementation, we observe critical mass phenomena for digital mobile telephony, and that differences in takeoff price originate from different socioeconomic circumstances rather than different degrees of network effects. The competitiveness of a market, however, has an important effect on the existence of critical mass, which may be an indication that multiple competitors reduce the perceived network benefits for consumers due to splintering (Kretschmer, 2008) and imperfect compatibility driven by on- net call discounts (Grajek, 2009).

So how does our method compare to existing heuristics of sales takeoff? First, and most important, we are able to estimate the range of prices for which takeoff of sales occurs. This is especially helpful for making strategic decisions about launch strategies, and about introductory pricing in particular. Existing models of sales takeoff do not specify the role of price in such detail. Second, our method can accommodate in the same estimation procedure different markets in terms of size and income heterogeneity, which is important for crosscountry or even cross-technology comparison. Existing work on sales takeoff typically looks at a single market (often the US market) and measures sales thresholds in absolute numbers, which would be misleading across international markets. Third, we identify two "diffusion regimes" over time, one in which diffusion is driven by changes in price (along the 
downward-sloping parts of the demand curve), and one in which diffusion occurs endogenously without further price changes (in the critical mass region of demand). Sales takeoff models do not distinguish between these two, considering periods of faster and slower growth without considering the underlying drivers. Fourth, we show that competitiveness of markets matters for the existence of critical mass phenomena in consumer demand for new technologies, a new result which has not been documented before.

Despite the limitations inevitably imposed by our simple model, we believe it to be sufficiently flexible to be applied it to a variety of empirical settings. In particular, it can be modified to take account of between network competition at the firm rather than market level (Grajek, 2009), as well as integrate richer information about the distribution of tastes in a population (Economides and Himmelberg, 1995). As our empirical implementation shows, the model yields interesting new insights about critical mass phenomena without requiring too much data detail. In summary, we believe that our model offers a practical and effective alternative to existing models of critical mass, which helps highlight novel, previously underresearched aspects of technologically dynamic markets. 


\section{References}

Agarwal, R., B. Bayus (2002), "The Market Evolution and Sales Takeoff of Product Innovations," Management Science 48(8), 1024-1041.

Bass F.M. (1969), “A New Product Growth Model for Consumer Durables,” Management Science 15(5), 215-227.

Cabral L. (1990), "On the Adoption of Innovations with 'Network' Externalities," Mathematical Social Sciences 19, 299-308.

Cabral, L. (2006), "Equilibrium, Epidemic and Catastrophe: Diffusion of Innovations with Network Effects," in: C. Antonelli, B. Hall, D. Foray and E. Steinmueller (Eds), New Frontiers in the Economics of Innovation and New Technology: Essays in Honor of Paul David, Edward Elgar, London, 427-437.

Cantillon, E., P. Yin (2008), “Competition between Exchanges: Lessons from the Battle of the Bund," CEPR Discussion Paper 6923.

Cool, K., I. Dierickx, G. Szulanski (1997), "Diffusion of Innovations within Organizations: Electronic Switching in the Bell System, 1971-1982," Organization Science 8(5), 543559.

Dubé, J., G. Hitsch, P. Chintagunta (2009), “Tipping and Concentration in Markets with Indirect Network Effects” Forthcoming, Marketing Science.

Economides, N., Ch. Himmelberg (1995), "Critical Mass and Network Evolution in Telecommunications," in: Gerard Brock (Ed.), 1995, Toward a Competitive Telecommunications Industry: Selected Papers from the 1994 Telecommunications Policy Research Conference.

Farrell, J., P. Klemperer (2007), "Coordination and Lock-In: Competition with Switching Costs and Network Effects," in: M. Armstrong and R. Porter (Eds.), Handbook of Industrial Organization, Vol. 3, Elsevier, Amsterdam, 1967-2072.

Gandal, N., M. Kende, R. Rob (2000), "The Dynamics of Technological Adoption in Hardware/Software Systems: The Case of Compact Disc Players," RAND Journal of Economics 31, 43-61.

Golder, P., G. Tellis (1997), "Will it Ever Fly? Modeling the Takeoff of Really New Consumer Durables," Marketing Science 16(3), 256-270.

Gowrisankaran, G., J. Stavins (2004), "Network Externalities and Technology Adoption: Lessons from Electronic Payments," RAND Journal of Economics 35, 260-276. 
Grajek, M. (2009), "Estimating Network Effects and Compatibility: Evidence from the Polish Mobile Market," Information Economics and Policy, Forthcoming.

Grajek, M., T. Kretschmer (2009), "Usage and Diffusion of Cellular Telephony, 1998-2004," International Journal of Industrial Organization 27(2), 238-249.

Granovetter, M. (1978), “Threshold Models of Collective Behavior,” American Journal of Sociology 83(6), 1420-1443.

Gruber, H., F. Verboven (2001), "The Evolution of Markets under Entry and Standards Regulation - The Case of Global Mobile Telecommunications," International Journal of Industrial Organization 19(7), 1189-1212.

Hartmann, W., P. Manchanda, H. Nair, M.Bothnew, P. Dodds, D. Godes, K. Hosanagar, C. Tucker (2008), "Modeling Social Interactions: Identification, Empirical Methods and Policy Implications," Marketing Letters 19(3), 287-304.

Jenkins, M., P. Liu, R. Matzkin, D. McFadden (2004), “The Browser War - Econometric Analysis of Markov Perfect Equilibrium in Markets with Network Effects," Working Paper, University of Berkeley.

Katz, M., C. Shapiro (1985), "Network Externalities, Competition and Compatibility," American Economic Review 75(3), 424-440.

Koski, H., T. Kretschmer (2005), "Entry, Standards and Competition: Firm Strategies and the Diffusion of Mobile Telephony," Review of Industrial Organization 26(1), 89-113.

Koski, H., T. Kretschmer (2004), “Competing in Network Industries: Firm Strategies, Market Outcomes, and Policy Implications," Journal of Industry, Competition and Trade 4(1), 531.

Kretschmer, T. (2008), "Splintering and Inertia in Network Industries," Journal of Industrial Economics 56(4), 685-706.

Lee, J., J. Lee; H. Lee (2003), „Exploration and Exploitation in the Presence of Network Externalities,” Management Science 49(4), 553-570.

Loch, C., B. Huberman (1999), "A Punctuated-Equilibrium Model of Technology Diffusion," Management Science 45(2), 160-177.

Mahajan, V., E. Muller, R. Srivastava (1990), "Determination of Adopter Categories by Using Innovation Diffusion Models," Journal of Marketing Research 27(1), 37-50.

Mahajan, V., E. Muller, F. Bass (1995), "Diffusion of New Products: Empirical Generalizations and Managerial Uses," Marketing Science 14, 79-88. 
Mahler, A., E. Rogers, (1999), “The Diffusion of Interactive Communication Innovations and the Critical Mass: The Adoption of Telecommunications Services by German Banks," Telecommunications Policy 23, 719-740.

Markus, L. (1987), “Toward a 'Critical Mass' Theory of Interactive Media: Universal Access, Interdependence and Diffusion," Communication Research 14, 491-511.

Rogers, E. (2003), Diffusion of Innovations, $5^{\text {th }}$ Ed., Free Press, New York.

Rohlfs J. (1974), “A Theory of Interdependent Demand for a Communications Service,” Bell Journal of Economics 5(1), 16-37.

Saloner, G., A. Shepard (1995), “Adoption of Technologies with Network Externalities: An Empirical Examination of the Adoption of Automated Teller Machines," RAND Journal of Economics 26, 479-501.

Shapiro, C., H. Varian (1999), Information Rules: A Strategic Guide to the Network Economy, Harvard Business School Press, Cambridge.

Stremersch, S., G. Tellis, P. Franses, J. Binken (2007), "Indirect Network Effects in New Product Growth,” Journal of Marketing 71(3), 52-74.

Sultan, F., J.U. Farley, D.R. Lehmann (1990), “A Meta-Analysis of Application of Diffusion Models," Journal of Marketing Research 27, 70-77.

Swann, P. (2002), "The Functional Form of Network Effects," Information Economics and Policy 14(3), 417-429.

Tellis, G.J., S. Stremersch, E. Yin (2003), “The International Takeoff of New Products: The Role of Economics, Culture, and Country Innovativeness," Marketing Science 22 (2), 188-208.

Tellis, G.J., E. Yin, R. Niraj (2009), "Does Quality Win? Network Effects versus Quality in High-Tech Markets," Journal of Marketing Research 46(2), 135-149.

Van den Bulte, Ch., G.L. Lilien (2001), "Medical Innovation Revisited: Social Contagion versus Marketing Effort," American Journal of Sociology 106, 1409-1435.

Van den Bulte, Ch., S. Stremersch (2004), "Social Contagion and Income Heterogeneity in New Product Diffusion: A Meta-Analytic Test,” Marketing Science 23 (4), 530-544. 
Figure 1. Stable vs. unstable equilibria

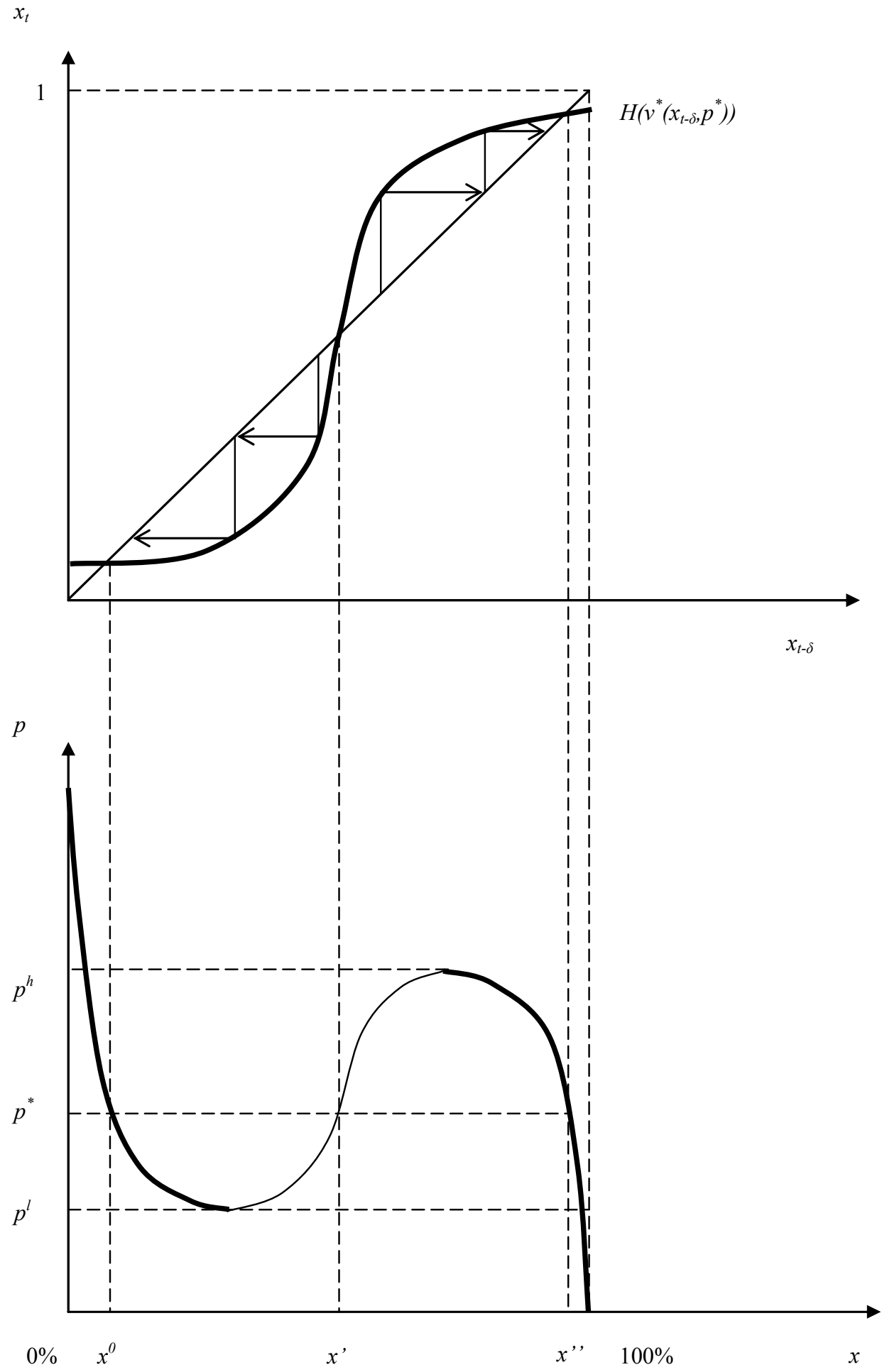


Figure 2. Critical mass in the mobile telephone market: Simulation of long-run demand using estimated model parameters
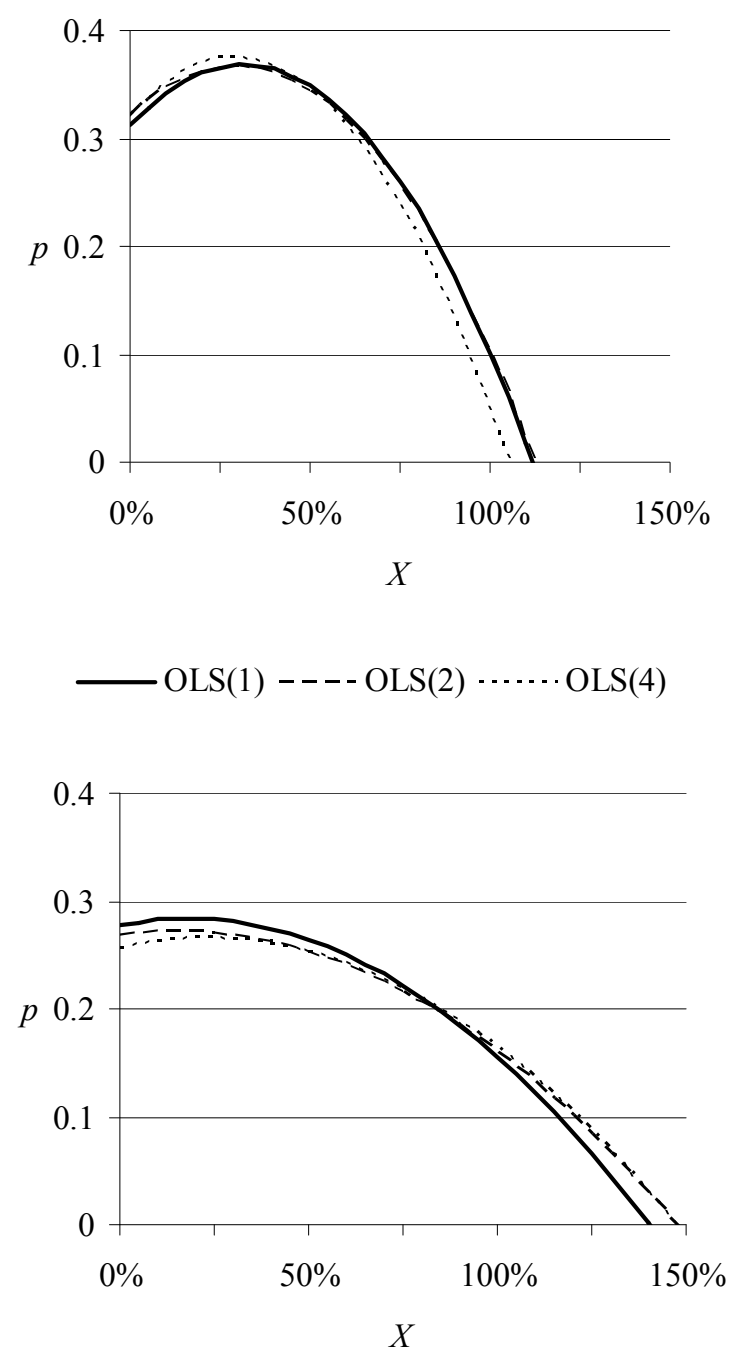

$-\operatorname{IV}(1)----\operatorname{IV}(2) \cdots \cdots \cdot \operatorname{IV}(4)$ 
Figure 3. Separating country groups: Long-run demand and competitiveness
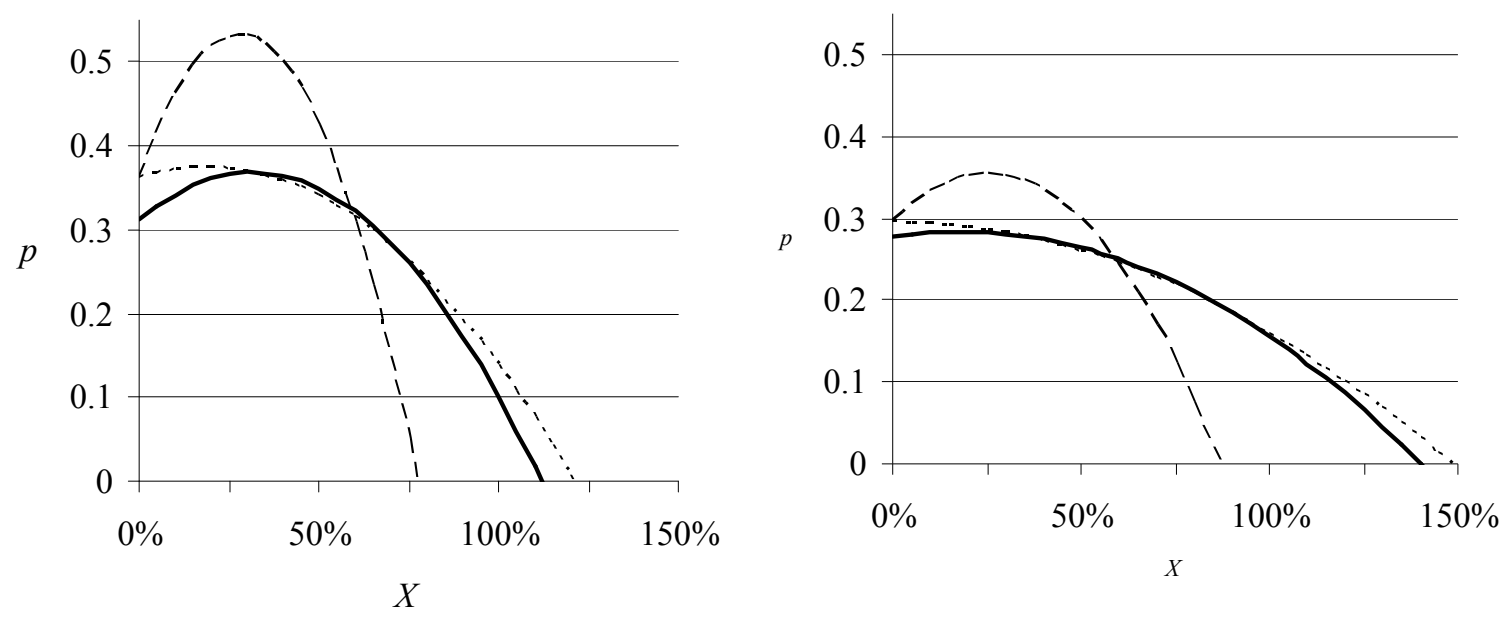

— OLS(1) - - - - Low Comp - . . . High Comp

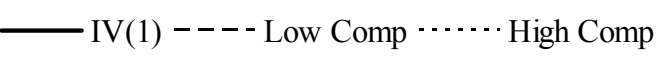


Figure 4. Sensitivity of long-run demand to changes in the network effect parameters

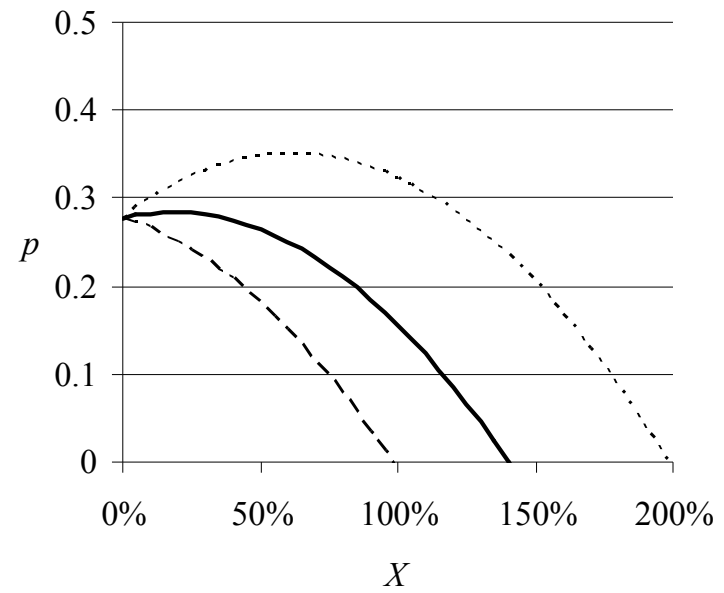

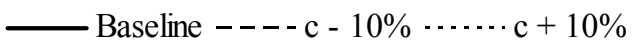

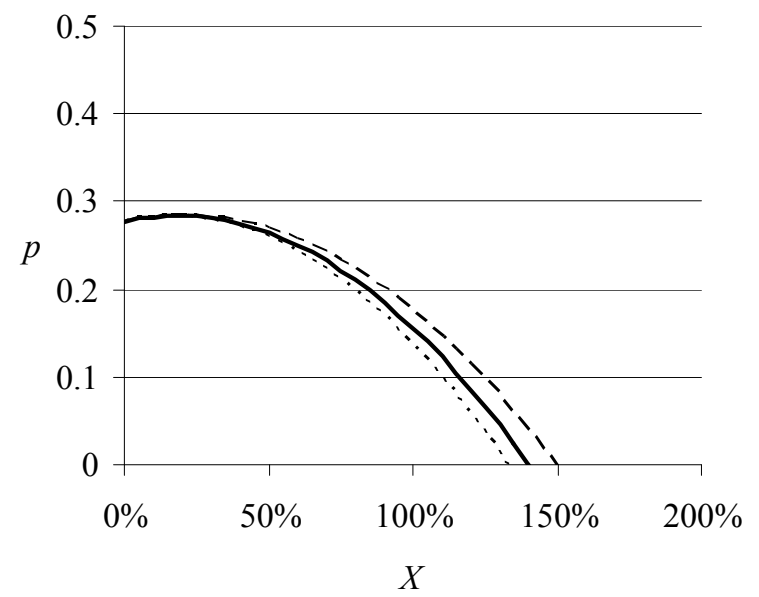

- Baseline -- - $\mathrm{d}-10 \% \cdots \cdots \cdot \mathrm{d}+10 \%$ 
Figure 5. Sensitivity of long-run demand to changes in the taste distribution parameters
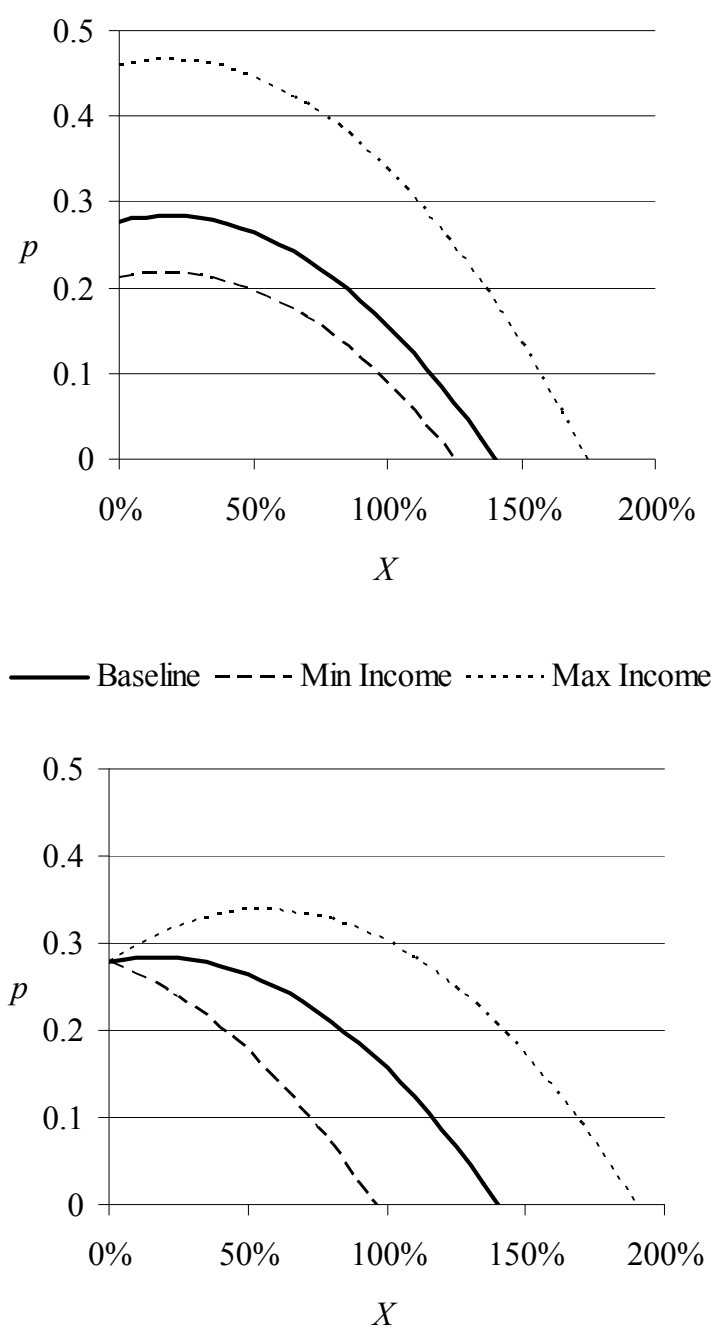

$\longrightarrow$ Baseline $----b-10 \% \cdot \cdots \cdot b+10 \%$ 
Table 1. Descriptive statistics

\begin{tabular}{llcccc}
\hline Variable & Variable Name & Mean & Std. Dev. & Min & Max \\
\hline Mobile Users/Head & MOB_PEN & .676 & .317 & .009 & 1.484 \\
Mobile Users/Head Squared & MOB_PEN_SQ & .557 & .424 & .00008 & 2.202 \\
GDP/Head & GDP_HEAD & 21.469 & 13.916 & .870 & 77.589 \\
Population (in millions) & POP & 80.090 & 209.500 & 3.813 & 1329.48 \\
Average Price/Minute & PRICE_AVE & .200 & .089 & .019 & .870 \\
Others' Average Price & PRICE_AVE_INST & .217 & .085 & .070 & .770 \\
Above median GDP/Head & RICH & .504 & .500 & 0 & 1 \\
First to adopt 2G & PIONEER & .231 & .422 & 0 & 1 \\
More than two competitors & COMP & .916 & .277 & 0 & 1 \\
\hline
\end{tabular}

Table 2. Estimation results

\begin{tabular}{|c|c|c|c|c|c|c|}
\hline & (1) & (2) & (3) & (4) & (5) & (6) \\
\hline EST METHOD & OLS & OLS & OLS & IV & IV & IV \\
\hline LAG & 1 quarter & 2 quarters & 4 quarters & 1 quarter & 2 quarters & 4 quarters \\
\hline \multirow[t]{2}{*}{ GDP_HEAD } & $0.001^{* * *}$ & $0.003^{* * *}$ & $0.005^{* * *}$ & $0.002^{* * *}$ & $0.004^{* * *}$ & $0.006^{* * *}$ \\
\hline & $(0.000)$ & $(0.001)$ & $(0.001)$ & $(0.001)$ & $(0.001)$ & $(0.001)$ \\
\hline \multirow[t]{2}{*}{ PRICE_AVE } & $-0.259^{* * *}$ & $-0.528^{* * *}$ & $-0.818^{* * *}$ & $-0.623^{* * *}$ & $-1.304^{* * *}$ & $-2.194^{* * * *}$ \\
\hline & $(0.076)$ & $(0.106)$ & $(0.113)$ & $(0.151)$ & $(0.219)$ & $(0.261)$ \\
\hline \multirow[t]{2}{*}{ L_MOB_PEN } & $1.091^{* * *}$ & $1.163^{* * *}$ & $1.307^{* * *}$ & $1.042^{* * *}$ & $1.060^{* * *}$ & $1.178^{* * *}$ \\
\hline & $(0.068)$ & $(0.101)$ & $(0.116)$ & $(0.076)$ & $(0.120)$ & $(0.155)$ \\
\hline \multirow[t]{2}{*}{ L_MOB_PEN_SQ } & $-0.147^{* *}$ & $-0.279^{* * *}$ & $-0.529^{* * *}$ & $-0.118^{*}$ & $-0.202^{* *}$ & $-0.379^{* * * *}$ \\
\hline & $(0.065)$ & $(0.093)$ & $(0.102)$ & $(0.065)$ & $(0.095)$ & $(0.116)$ \\
\hline \multirow[t]{2}{*}{ CONSTANT } & $0.049^{* * *}$ & $0.101^{* * *}$ & $0.156^{* * *}$ & $0.129^{* * *}$ & $0.264^{* * *}$ & $0.420^{* * *}$ \\
\hline & $(0.016)$ & $(0.023)$ & $(0.027)$ & $(0.035)$ & $(0.055)$ & $(0.067)$ \\
\hline \multirow[t]{2}{*}{ AUTOCORRELATION } & $0.055^{* *}$ & $0.557^{* * *}$ & $0.798^{* * * *}$ & $0.223^{* * *}$ & $0.648^{* * * *}$ & $0.785^{* * *}$ \\
\hline & $(0.026)$ & $(0.049)$ & $(0.032)$ & $(0.072)$ & $(0.064)$ & $(0.042)$ \\
\hline ADJ_R_SQ & 0.892 & 0.797 & 0.654 & 0.894 & 0.770 & 0.537 \\
\hline $\mathrm{N}--$ & 1134 & 1134 & 1134 & 1112 & 1112 & 1112 \\
\hline
\end{tabular}

${ }^{*} \mathrm{p}<0.1,{ }^{* *} \mathrm{p}<0.05,{ }^{* * *} \mathrm{p}<0.01$

Heteroscedasticity- and autocorrelation-robust standard errors in parentheses. 
Table 3. Identified structural parameters

\begin{tabular}{|c|c|c|c|c|c|c|}
\hline $\begin{array}{l}\text { EST METHOD } \\
\text { LAG }\end{array}$ & $\begin{array}{c}(1) \\
\text { OLS } \\
1 \text { quarter }\end{array}$ & $\begin{array}{c}(2) \\
\text { OLS } \\
2 \text { quarters }\end{array}$ & $\begin{array}{c}(3) \\
\text { OLS } \\
4 \text { quarters }\end{array}$ & $\begin{array}{c}\text { (4) } \\
\text { IV } \\
1 \text { quarter }\end{array}$ & $\begin{array}{c}(5) \\
\text { IV } \\
2 \text { quarters }\end{array}$ & $\begin{array}{c}\text { (6) } \\
\text { IV } \\
4 \text { quarters }\end{array}$ \\
\hline $\mathrm{a} 0$ & $\begin{array}{l}0.188^{* * *} \\
(0.056)\end{array}$ & $\begin{array}{l}0.191^{* * *} \\
(0.040)\end{array}$ & $\begin{array}{l}0.191^{* * *} \\
(0.029)\end{array}$ & $\begin{array}{l}0.207^{* * *} \\
(0.030)\end{array}$ & $\begin{array}{l}0.203^{* * *} \\
(0.023)\end{array}$ & $\begin{array}{l}0.191^{* * *} \\
(0.019)\end{array}$ \\
\hline a1 & $\begin{array}{l}0.006^{* * * *} \\
(0.001)\end{array}$ & $\begin{array}{l}0.006^{* * * *} \\
(0.001)\end{array}$ & $\begin{array}{l}0.006^{* * *} \\
(0.001)\end{array}$ & $\begin{array}{l}0.003^{* * *} \\
(0.000)\end{array}$ & $\begin{array}{l}0.003^{* * *} \\
(0.000)\end{array}$ & $\begin{array}{l}0.003^{* * *} \\
(0.000)\end{array}$ \\
\hline b & $\begin{array}{l}0.259^{* * * *} \\
(0.076)\end{array}$ & $\begin{array}{l}0.528^{* * * *} \\
(0.106)\end{array}$ & $\begin{array}{l}0.818^{* * * *} \\
(0.113)\end{array}$ & $\begin{array}{l}0.623^{* * *} \\
(0.151)\end{array}$ & $\begin{array}{l}1.304^{* * *} \\
(0.219)\end{array}$ & $\begin{array}{c}2.194^{* * *} \\
(0.261)\end{array}$ \\
\hline c & $\begin{array}{l}4.220^{* * * *} \\
(1.184)\end{array}$ & $\begin{array}{l}2.204^{* * *} \\
(0.441)\end{array}$ & $\begin{array}{l}1.598^{* * *} \\
(0.260)\end{array}$ & $\begin{array}{l}1.674^{* * *} \\
(0.435)\end{array}$ & $\begin{array}{l}0.813^{* * *} \\
(0.184)\end{array}$ & $\begin{array}{c}0.537^{* * *} \\
(0.110)\end{array}$ \\
\hline $\mathrm{d}$ & $\begin{array}{l}-0.570^{* *} \\
(0.221)\end{array}$ & $\begin{array}{c}-0.529^{* * *} \\
(0.168)\end{array}$ & $\begin{array}{c}-0.647^{* * *} \\
(0.147)\end{array}$ & $\begin{array}{l}-0.190^{*} \\
(0.104)\end{array}$ & $\begin{array}{c}-0.155^{* *} \\
(0.079)\end{array}$ & $\begin{array}{c}-0.173^{* * *} \\
(0.062)\end{array}$ \\
\hline
\end{tabular}

${ }^{*} \mathrm{p}<0.1,{ }^{* *} \mathrm{p}<0.05,{ }^{* * *} \mathrm{p}<0.01$

Standard errors calculated with the delta method based on the coefficients in Table 2. 
Table 4. Separating country groups: Estimation results with interaction terms

\begin{tabular}{|c|c|c|c|c|c|c|}
\hline $\begin{array}{l}\text { EST METHOD } \\
\text { LAG }\end{array}$ & $\begin{array}{c}(1) \\
\text { OLS } \\
1 \text { quarter }\end{array}$ & $\begin{array}{c}(2) \\
\text { OLS } \\
1 \text { quarter }\end{array}$ & $\begin{array}{c}(3) \\
\text { OLS } \\
1 \text { quarter }\end{array}$ & $\begin{array}{c}\text { (4) } \\
\text { IV } \\
1 \text { quarter }\end{array}$ & $\begin{array}{c}(5) \\
\text { IV } \\
1 \text { quarter }\end{array}$ & $\begin{array}{c}\text { (6) } \\
\text { IV } \\
1 \text { quarter }\end{array}$ \\
\hline GDP_HEAD & $\begin{array}{l}0.002^{* * *} \\
(0.001)\end{array}$ & $\begin{array}{l}0.001^{* * *} \\
(0.000)\end{array}$ & $\begin{array}{l}0.002^{* * *} \\
(0.001)\end{array}$ & $\begin{array}{l}0.002^{* * *} \\
(0.001)\end{array}$ & $\begin{array}{l}0.002^{* * *} \\
(0.001)\end{array}$ & $\begin{array}{l}0.002^{* * *} \\
(0.001)\end{array}$ \\
\hline PRICE_AVE & $\begin{array}{c}-0.248^{* * *} \\
(0.076)\end{array}$ & $\begin{array}{c}-0.258^{* * *} \\
(0.076)\end{array}$ & $\begin{array}{c}-0.266^{* * *} \\
(0.074)\end{array}$ & $\begin{array}{c}-0.639^{* * *} \\
(0.155)\end{array}$ & $\begin{array}{c}-0.650^{* * *} \\
(0.157)\end{array}$ & $\begin{array}{c}-0.557^{* * *} \\
(0.121)\end{array}$ \\
\hline L_MOB_PEN & $\begin{array}{l}1.097^{* * * *} \\
(0.070)\end{array}$ & $\begin{array}{l}1.092^{* * *} \\
(0.084)\end{array}$ & $\begin{array}{l}1.324^{* * *} \\
(0.145)\end{array}$ & $\begin{array}{c}0.997^{* * *} \\
(0.084)\end{array}$ & $\begin{array}{l}1.010^{* * *} \\
(0.092)\end{array}$ & $\begin{array}{l}1.261^{* * *} \\
(0.146)\end{array}$ \\
\hline L_MOB_PEN_SQ & $\begin{array}{l}-0.150^{* *} \\
(0.073)\end{array}$ & $\begin{array}{l}-0.149^{*} \\
(0.082)\end{array}$ & $\begin{array}{c}-0.579^{* * * *} \\
(0.181)\end{array}$ & $\begin{array}{l}-0.071 \\
(0.074)\end{array}$ & $\begin{array}{l}-0.087 \\
(0.081)\end{array}$ & $\begin{array}{c}-0.518^{* * *} \\
(0.177)\end{array}$ \\
\hline L_MOB_PEN*RICH & $\begin{array}{l}-0.063 \\
(0.068)\end{array}$ & & & $\begin{array}{c}0.035 \\
(0.069)\end{array}$ & & \\
\hline L_MOB_PEN_SQ ${ }^{*} \mathrm{RICH}$ & $\begin{array}{c}0.022 \\
(0.083)\end{array}$ & & & $\begin{array}{l}-0.063 \\
(0.083)\end{array}$ & & \\
\hline L_MOB_PEN"PIONEER & & $\begin{array}{c}0.002 \\
(0.066)\end{array}$ & & & $\begin{array}{c}0.090 \\
(0.071)\end{array}$ & \\
\hline L_MOB_PEN_SQ*PIONEER & & $\begin{array}{c}0.002 \\
(0.082)\end{array}$ & & & $\begin{array}{l}-0.098 \\
(0.085)\end{array}$ & \\
\hline L_MOB_PEN*COMP & & & $\begin{array}{c}-0.287^{* *} \\
(0.132)\end{array}$ & & & $\begin{array}{c}-0.264^{* *} \\
(0.133)\end{array}$ \\
\hline L_MOB_PEN_SQ* ${ }^{*}$ COMP & & & $\begin{array}{l}0.483^{* * *} \\
(0.175)\end{array}$ & & & $\begin{array}{l}0.445^{* *} \\
(0.173)\end{array}$ \\
\hline CONSTANT & $\begin{array}{c}0.040^{* * *} \\
(0.015)\end{array}$ & $\begin{array}{c}0.049^{* * *} \\
(0.018)\end{array}$ & $\begin{array}{l}0.050^{* * *} \\
(0.014)\end{array}$ & $\begin{array}{l}0.135^{* * *} \\
(0.037)\end{array}$ & $\begin{array}{c}0.138^{* * *} \\
(0.038)\end{array}$ & $\begin{array}{l}0.116^{* * * *} \\
(0.027)\end{array}$ \\
\hline AUTOCORRELATION & $\begin{array}{c}0.048 \\
(0.032)\end{array}$ & $\begin{array}{l}0.056^{* *} \\
(0.026)\end{array}$ & $\begin{array}{l}0.136^{* * *} \\
(0.047)\end{array}$ & $\begin{array}{l}0.200^{* *} \\
(0.078)\end{array}$ & $\begin{array}{l}0.231^{* * * *} \\
(0.076)\end{array}$ & $\begin{array}{l}0.265^{* * *} \\
(0.077)\end{array}$ \\
\hline ADJ_R_SQ & 0.893 & 0.892 & 0.904 & 0.894 & 0.893 & 0.908 \\
\hline $\mathrm{N}$ & 1134 & 1134 & 1134 & 1112 & 1112 & 1112 \\
\hline
\end{tabular}

${ }^{*} \mathrm{p}<0.1,{ }^{* *} \mathrm{p}<0.05,{ }^{* * *} \mathrm{p}<0.01$

Heteroscedasticity- and autocorrelation-robust standard errors in parentheses. 


\section{Appendix}

\section{A.1. Derivatives of the function $H($.$) with respect to x_{t-\delta}$ and $p$}

For simplicity, we slightly abuse the notation in this section by treating price as a constant parameter $p$. Recall that $v_{t}{ }^{*}$ is an implicit function of $x_{t-\delta}$ and $p$ is defined by

(A.1) $u\left(v_{t}^{*}, x_{t-\delta}\right)=p$.

To calculate the derivative of $H$ with respect to the lagged network size $x_{t-\delta}$, we first apply the chain rule to the definition of $H($.) given in (3). We obtain

$$
\frac{\partial}{\partial x_{t-\delta}} H\left(v_{t}^{*}\right)=-\frac{\partial F\left(v_{t}^{*}\right)}{\partial v_{t}^{*}} \cdot \frac{\partial v_{t}^{*}}{\partial x_{t-\delta}}
$$

The first term on the RHS of (A.2) is just the density of $v$ at $v_{t}{ }^{*}$. To calculate the second term, note that the total derivative of $u\left(v_{t}{ }^{*}, x_{t-\delta}\right)$ with respect to $x_{t-\delta}$ must stay constant in order to satisfy equation (A.1). This holds for

$$
\frac{\partial u\left(v_{t}^{*}, x_{t-\delta}\right)}{\partial x_{t-\delta}}=-\frac{\partial u\left(v_{t}^{*}, x_{t-\delta}\right.}{\partial v_{t}^{*}} \cdot \frac{\partial v_{t}^{*}}{\partial x_{t-\delta}}
$$

Solving (A.3) for $\frac{\partial v_{t}^{*}}{\partial x_{t-\delta}}$ and substituting that into (A.2) yields

$$
\frac{\partial}{\partial x_{t-\delta}} H\left(v_{t}^{*}\right)=f\left(v_{t}^{*}\right) \cdot\left(\frac{\partial u\left(v_{t}^{*}, x_{t-\delta}\right.}{\partial v_{t}^{*}}\right)^{-1} \cdot \frac{\partial u\left(v_{t}^{*}, x_{t-\delta}\right)}{\partial x_{t-\delta}}
$$

where $f$ is the density function of $v$.

Examination of (A.4) gives the following lemma.

Lemma 1: Whenever the solution to equation (2) exists and is unique so that $v_{t}{ }^{*}$ is well defined, the extent of network externalities measured by $\eta \equiv \frac{\partial u\left(v_{t}^{*}, x_{t-\delta}\right)}{\partial x_{t-\delta}}$ determines the slope of the function $H$ in the $x_{t-\delta}$ domain, such that (i) $H$ is non-decreasing if and only if network effects are non-negative, 
(ii) the slope of $H$ equals zero if there are no network effects, and

(iii) the slope of $H$ increases with network effects whenever the density of types is strictly positive.

Proof of Lemma 1: According to (A.4), the slope of function $H$ in the $x_{t-\delta}$ domain is determined by a product of the three components: density of consumer types, inverse of the partial derivative of the willingness-to-pay function with respect to consumer type, and partial derivative of the willingness-to-pay function with respect to the installed base, all evaluated at the indifferent type $v_{t}{ }^{*}$. The first component of this product is non-negative (density function), the second is positive (due to the assumed rank ordering), and the third is the extent of network effects.

Analogously, to calculate the derivative of $H$ with respect to the price $p$ we first apply the chain rule to obtain

$$
\frac{\partial}{\partial p} H\left(v_{t}^{*}\right)=-\frac{\partial F\left(v_{t}^{*}\right)}{\partial v_{t}^{*}} \cdot \frac{\partial v_{t}^{*}}{\partial p} .
$$

Then we note that from (A.1) we have

$$
\frac{\partial u\left(v_{t}^{*}, x_{t-\delta}\right)}{\partial v_{t}^{*}} \cdot \frac{\partial v_{t}^{*}}{\partial p}=1
$$

and substitute to get

$$
\frac{\partial}{\partial p} H\left(v_{t}^{*}\right)=-f\left(v_{t}^{*}\right) \cdot\left(\frac{\partial u\left(v_{t}^{*}, x_{t-\delta}\right)}{\partial v_{t}^{*}}\right)^{-1} .
$$

Lemma 2 follows directly from examination of (A.7).

Lemma 2: Whenever the solution to equation (2) exists and is unique so that $v_{t}{ }^{*}$ is well defined, changes in price $p$ determine the shifts of the function $H$ in the $x_{t-\delta}$ domain, such that $H\left(v^{*}\left(x_{t-\delta}, p^{\prime}\right) \geq H\left(v^{*}\left(x_{t-\delta}, p^{\prime \prime}\right)\right.\right.$ for every $x_{t-\delta}$ and $H\left(v^{*}\left(x_{t-\delta}, p^{\prime}\right)>H\left(v^{*}\left(x_{t-}\right.\right.\right.$ $\left.\delta, p^{\prime \prime}\right)$ for at least some $x_{t-\delta}$ if $p^{\prime<p}$ '. 
Proof of Lemma 2: Because the density of types is by definition non-negative (and strictly positive over some range), and the derivative of the willingness-to-pay function with respect to consumer type is positive due to the assumed rank ordering, (A.7) is always non-negative and strictly positive for at least some values of the installed base $x_{t-\delta}$.

\section{A.2. Proofs of Propositions}

Proof of Proposition 1: First, we prove that the downward-sloping parts of the long-run demand consist of stable equilibria and the upward-sloping parts are unstable. The long-run demand condition (5) implies that the long-run equlibria in our model correspond to the fixed points of the function $H($.$) . The stable fixed points of the function H($.$) are the long-run$ attractors of the dynamic process described by equation (4) (illustrated by the arrows in the upper panel of Figure 1). This means that for a fixed point to be stable, the function $H($.) must cross the 45-degree line from above. The reverse is true at unstable fixed points (critical mass points): the function $H($.$) must cross the 45-degree line from below. It follows that a price$ decrease that shifts the function $H($.$) upwards (Lemma 2) moves the stable fixed points to the$ right and the unstable ones to the left. Hence, downward-sloping parts of long-run demand must consist of stable, and upward-sloping parts of unstable, equlibria.

Second, we prove that network effects must be strong enough for the unstable equilibria to exist. For an unstable equilibrium to exist, the function $H($.$) must cross the 45-degree line$ from below, which is possible if and only if the network effects are strong enough. This follows from Lemma 1, which shows that the slope of function $H($.$) increases with, and is$ zero without, network effects.

Proof of Proposition 2: The first part of Proposition 2 follows immediately from Proposition 1, which says that unstable equilibria are located on the upward-sloping part of the long-run demand function. Whenever critical mass exists, an increased (decreased) price leads to a higher (lower) critical mass. The second part of Proposition 2 follows from Lemma 1. It 
states that the slope of $H($.) increases with network effects whenever the density of types is positive. Suppose that $x^{\prime}$ is a critical mass point, that is, there exists a price $p^{*}$ for which $H($. crosses the 45-degree line from below at $x$ '. Therefore, there must exist a neighborhood of $x$ ', $\left[\underline{x}^{\prime}, \overline{x^{\prime}}\right]$, such that $\underline{x}^{\prime}<x_{1}<\overline{x^{\prime}}$ and $H($.$) has a positive slope over \left[\underline{x}^{\prime}, \overline{x^{\prime}}\right]$. Note that the density of types that corresponds to $\left[\underline{x}^{\prime}, \overline{x^{\prime}}\right]$ and $p^{*}$ must be strictly positive for $H($.$) to have a positive$ slope over $\left[\underline{x}^{\prime}, \overline{x^{\prime}}\right]$ (Lemma 1). An increase in network effects in the neighborhood $\left[\underline{x}^{\prime}, \overline{x^{\prime}}\right]$ thus increases the slope of $H($.$) over the entire neighborhood, shifting the critical mass point x$ ' to the left.

\section{A.3. Relation to the Bass (1969) model}

In this Appendix, we illustrate that our model applied to a single market simplifies to the original Bass (1969) diffusion equation. First, we specify consumer v's willingness-to-pay function in a single market as follows:

(A.8) $u\left(v, x_{t-1}\right)=v+c x_{t-1}+d x_{t-1}^{2}$,

where $c$ and $d$ are parameters that determine the extent of network effects, with the square term capturing possible nonlinearities, as before. Fuerther, assume $v$ to be uniformly distributed over $(-\infty, a]$ with density $b>0$. Given these functional forms, diffusion equation (4) becomes

(A.9) $x_{t}=a b-b p_{t}+b c x_{t-1}+b d x_{t-1}^{2}$.

The structural parameters of this model can be recovered from the coefficients of the following estimation equation:

(A.9) $x_{t}=\alpha+\beta p_{t}+\gamma_{1} x_{t-1}+\gamma_{2} x_{t-1}^{2}+\varepsilon_{t}$, 
where $\varepsilon_{t}$ denotes the error term. Equation (A.9) simplifies to the original Bass model if $\beta=0$. To see this, rearrange the terms to obtain:

(A.10) $x_{t}-x_{t-1}=\alpha+\left(\gamma_{1}-1\right) x_{t-1}+\gamma_{2} x_{t-1}^{2}+\varepsilon_{t}$.

The left-hand side of (A.10) corresponds to sales at $t$ and the right-hand side is a square function of cumulative sales through period $t$ - 1 , which matches exactly the discrete analog of the Bass (1969) diffusion equation. 




\section{Recent ESMT Working Papers}

\begin{tabular}{|c|c|c|}
\hline & $\begin{array}{c}\text { ESMT } \\
\text { No. }\end{array}$ & $\begin{array}{c}\text { Competence } \\
\text { Center }\end{array}$ \\
\hline $\begin{array}{l}\text { Estimating Critical Mass in the Global Cellular Telephony Market } \\
\text { Michat Grajek, ESMT } \\
\text { Tobias Kretschmer, Ludwig-Maximilians-Universität München }\end{array}$ & 08-004R1 & $\begin{array}{l}\text { Management } \\
\text { and } \\
\text { Technology }\end{array}$ \\
\hline $\begin{array}{l}\text { Marketing Social Responsibility } \\
\text { Sumitro Banerjee, ESMT } \\
\text { Luc Wathieu, Ferrero Chair in International Marketing, ESMT }\end{array}$ & $10-002$ & $\begin{array}{l}\text { Management } \\
\text { and } \\
\text { Technology }\end{array}$ \\
\hline $\begin{array}{l}\text { Quantification of Harm in Damages Actions for Antitrust Infringements: } \\
\text { Insights from German Cartel Cases }\end{array}$ & $10-001$ & $\begin{array}{l}\text { European } \\
\text { Competitiveness }\end{array}$ \\
\hline $\begin{array}{l}\text { Hans W. Friederiszick, ESMT CA } \\
\text { Lars-Hendrik Röller, ESMT }\end{array}$ & & \\
\hline $\begin{array}{l}\text { A Framework for Monitoring Relational Quality in B2B Technology } \\
\text { Partnerships } \\
\text { Francis Bidault, ESMT } \\
\text { Manfred Lüth, University of Nice } \\
\text { Olaf Plötner, ESMT }\end{array}$ & $09-008$ & $\begin{array}{l}\text { Management } \\
\text { and } \\
\text { Technology }\end{array}$ \\
\hline $\begin{array}{l}\text { Enjoy! Assertive Language and Consumer Compliance in (Non)Hedonic } \\
\text { Contexts } \\
\text { Ann Kronrod, Tel-Aviv University } \\
\text { Amir Grinstein, Ben-Gurion University of the Negev } \\
\text { Luc Wathieu, Ferrero Chair in International Marketing, ESMT }\end{array}$ & 09-007 & $\begin{array}{l}\text { Management } \\
\text { and } \\
\text { Technology }\end{array}$ \\
\hline $\begin{array}{l}\text { ISO 9000: New Form of Protectionism or Common Language in } \\
\text { International Trade? }\end{array}$ & 09-006 & $\begin{array}{c}\text { European } \\
\text { Competitiveness }\end{array}$ \\
\hline $\begin{array}{l}\text { Joseph A. Clougherty, University of Illinois at Urbana-Champaign } \\
\text { Michat Grajek, ESMT }\end{array}$ & & \\
\hline $\begin{array}{l}\text { Demography vs. Context: A Cross-Country Survey of the Willingness to Rely } \\
\text { on Trust in Business Partnerships }\end{array}$ & 09-005 & \\
\hline $\begin{array}{l}\text { Francis Bidault, ESMT } \\
\text { José R. de la Torre, Florida International University } \\
\text { Stelios H. Zanakis, Florida International University }\end{array}$ & & Technology \\
\hline $\begin{array}{l}\text { Regulation and Investment in Network Industries: Evidence from European } \\
\text { Telecoms }\end{array}$ & 09-004 & $\begin{array}{c}\text { European } \\
\text { Competitiveness }\end{array}$ \\
\hline $\begin{array}{l}\text { Michat Grajek, ESMT } \\
\text { Lars-Hendrik Röller, ESMT }\end{array}$ & & \\
\hline $\begin{array}{l}\text { Access Regulation and Investment in Next Generation Networks: A Ranking } \\
\text { of Regulatory Regimes }\end{array}$ & $09-003$ & $\begin{array}{c}\text { European } \\
\text { Competitiveness }\end{array}$ \\
\hline $\begin{array}{l}\text { Rainer Nitsche, ESMT } \\
\text { Lars Wiethaus, ESMT }\end{array}$ & & \\
\hline $\begin{array}{l}\text { The Effect of Adversity on Process Innovations and Managerial Incentives } \\
\text { Benoit Dostie, HEC Montréal } \\
\text { Rajshri Jayaraman, ESMT }\end{array}$ & $09-002$ & $\begin{array}{l}\text { Management } \\
\text { and } \\
\text { Technology }\end{array}$ \\
\hline $\begin{array}{l}\text { An Empirical Approach to Understanding Privacy Concerns } \\
\text { Luc Wathieu, ESMT } \\
\text { Allan Friedman, John F. Kennedy School, Harvard University }\end{array}$ & 09-001 & $\begin{array}{l}\text { Management } \\
\text { and } \\
\text { Technology }\end{array}$ \\
\hline
\end{tabular}




\section{ESMT}

European School of Management and Technology GmbH

Schlossplatz 1

10178 Berlin

Germany

Phone: +49 (0)30212 31-1279

www.esmt.org 